\title{
A Simple Bio-preservation Technique to Increase Shelf Life of Ampalavi Mango Fruits Using Aloe vera Gel
}

\author{
Nivethika Ajeethan ${ }^{1}$ and Gunasingham Mikunthan ${ }^{2}$ \\ 1. Department of Biosystems Technology, Faculty of Technology, University of Jaffna, Ariviyal Nagar, Kilinochchi 44000, Sri Lanka \\ 2. Department of Agricultural Biology, Faculty of Agriculture, University of Jaffna, Ariviyal Nagar, Kilinochchi 44000, Sri Lanka
}

\begin{abstract}
Aloe vera is being identified as a potential medicinal plant for its application in industries as well as traditional usage. The gel obtained from the leaves of A. vera has numerous properties. In this study, using the gel to extend the shelf life of Ampalavi mango fruits was studied. Even sized, uniform coloured, matured Ampalavi cultivar mango fruits were surface cleaned and coated with $33 \%, 66 \%$ and $100 \%$ gel, respectively. Results revealed that the ripening was delayed due to the coating. The total soluble solid (TSS), $\mathrm{pH}$ and weight loss were high in uncoated fruits. The mean $\mathrm{pH}$ of the pulp from fruits kept as control was 4.94 at $4 \mathrm{~d}$ fruit preservation period (FPP) and was slightly increased to 5.43 within $12 \mathrm{~d} \mathrm{FPP,} \mathrm{whereas} \mathrm{the} \mathrm{minimal} \mathrm{pH} \mathrm{(4.69} \mathrm{at} 4 \mathrm{~d}$ FPP and 5.03 at 9 $\mathrm{d}$ FPP) was noticed in $100 \%$ gel coated fruits. The TSS (brix) was significantly in higher levels $\left(13.67{ }^{\circ} \mathrm{Bx}\right.$ within $4 \mathrm{~d}$ FPP and $20.77^{\circ} \mathrm{Bx}$ within $12 \mathrm{~d} \mathrm{FPP}$ ) in control fruits, whereas the minimum TSS value was $9.27^{\circ} \mathrm{Bx}$ and $18.03{ }^{\circ} \mathrm{Bx}$ within $4 \mathrm{~d}$ and $12 \mathrm{~d}$ FPP, respectively, recorded from the $100 \%$ gel coated fruits in storage. The weight loss percentage (WLP) was significantly $(P<0.05)$ higher in control fruits $(8.46 \%)$, whereas the lower WLP $(1.13 \%)$ was found in $100 \%$ gel coated fruits after $12 \mathrm{~d}$ of storage. This low-scale gel coating technique prolonged the fruits shelf life by delaying the fruit ripening. This effect has to be further investigated to commercialize the natural product for large scale ready-made application.
\end{abstract}

Key words: Aloe vera gel, total soluble solid, weight loss percentage, mango.

\section{Introduction}

The word aloe is derived from the word Arabic "Alloeh" or the Hebrew "Halal", meaning "bitter, shinny substance". At present, Aloe vera is widely distributed throughout the tropics and subtropics region of Sri Lanka. A. vera is a perennial plant with thick, thorn-edged leaves and gray to bright green in color. With the appearance of a cactus, but A. vera is in fact a member of the lily family (Liliaceae). A typical $A$. vera plant produces two or three yellow tubular flowers, shaped much like those of the Easter lily, and it flowers intermittently throughout the year. Its fleshy leaves help to survive long periods of drought, due to the fact that leaves of this plant can store water [1].

A. vera contains 75 potentially active constituents, such as vitamins, enzymes, minerals, sugars, lignin,

Corresponding author: Nivethika Ajeethan, B.Sc., research fields: agriculture and agricultural biology. saponins, salicylic acids and amino acids [2].

These natural preservative products are available in bulk quantity, and the simple and easy process of extraction, purification and sterilization makes it a standard product within a short processing time and not use of chemicals in their manufacture. Edible coatings of gel over fruits are used to improve their quality and shelf life [3].

A. vera gel has been proven one of the best edible and biologically safe preservative coatings for different types of foods, because of its film-forming properties, antimicrobial actions, biodegradability and biochemical properties. It is composed mainly of polysaccharides and acts as a natural barrier to moisture and oxygen, which are the main agents of deterioration of fruits and vegetables. A. vera gel has the ability to prolong shelf life of the fruits and vegetables by minimizing the rate of respiration and maintaining quality attributes (color, flavor, etc.). It 
has antifungal and antibacterial property, which provides a defensive barrier against microbial contamination of fruits and vegetable [4].

It could provide a greener alternative to sulphur dioxide and other synthetic food preservatives. Researchers in Spain have developed an edible coating from the gel that can prolong the freshness and safety of produce without affecting taste and appearance [5].

Kumar and Bhatnagar [3] reported that $A$. vera gel based edible coating has exhibited to prevent loss of moisture and firmness, control respiratory rate and maturation development, delay oxidative browning and reduce microorganism proliferation in fruits.

A. vera is a bio-preservative of table grapes, cherries, mangos, oranges and nectarines, and for increasing demands for environmentally friendly postharvest handling procedures [6]. The gel is useful in extending the shelf life of grapes [7] and sweet cherries [8]. The untreated grapes deteriorated rapidly within about $7 \mathrm{~d}$, whereas the gel-coated grapes were well-preserved for up to $35 \mathrm{~d}$ under the same conditions. Therefore the gel-treated grapes were firmer, had less weight loss and less color change than the untreated grapes [9]. Further, A. vera gel coating in oranges resulted in decrease in weight loss, increase in titrability of acids and higher total soluble solid (TSS) [3]. This A. vera gel coating technique prolonged the fruits shelf life by delaying the fruit ripening. So this study aimed to use A. vera gel to extend the shelf life of Ampalavi mango fruits.

\section{Materials and Methods}

\subsection{Ampalavi Mango Fruits}

Mango fruits of Ampalavi cultivar with even size, mature, uniform shaped, coloured, free from visual blemishes and diseases were obtained from a fruit stall supplied from a fruit orchard situated in Thirunelvely, Jaffna. These fruits were surface cleaned to remove all contaminants and fruit's gum to render a sound firm bonding. Soap water was used to wash the Ampalavi mango fruits thoroughly and shade dried to ensure cleaned fruit surface.

\subsection{Preparation of A. vera Gel}

The gel was prepared from matured leaves of $A$. vera plants. At first, leaves were washed with tap water, followed by $70 \%$ alcohol to sterilize the surface. Gel was then separated from the outer cortex of leaf, the colorless hydroparenchyma was grounded in a blender and resulting mixture was filtered to remove the fibers. According to Misir et al. [1], the gel was pasteurized at $70{ }^{\circ} \mathrm{C}$ for $45 \mathrm{~min}$, cooled immediately at ambient temperature for stabilization and $1 \%$ gelatine was used as a gelling agent to facilitate coating the gel [6].

\subsection{Experiment Design}

The experiment was conducted using completely randomized design. Thirty six even size Ampalavi fruits were obtained from an orchard and kept into four groups. Each group had nine Ampalavi fruits and were coated with $33 \%, 66 \%, 100 \%$ gel, respectively, while another group of nine fruits were not coated and kept as control $(0 \%)$. Gel dilutions were prepared using distilled water as $0 \%, 33 \%, 66 \%$ and $100 \%$, then fruits were dipped for 20-30 s into the gel. Fruits were shade dried and stored in wooden racks and stored at room condition $\left(31{ }^{\circ} \mathrm{C}, 85 \%-88 \%\right.$ relative humidity). Some fruit quality parameters, such as weight loss, $\mathrm{pH}$ and TSS were measured.

The fruits were peeled, sliced and blended to prepare juice. The $\mathrm{pH}$ of fruit juice was measured by using digital $\mathrm{pH}$ meter (Hach model). TSS was determined using hand refrectometer at room temperature. The extracted juice from each lot was shaken well, the representative samples were placed on dry refrectometer prism and readings were taken directly. Weight loss was determined during storage. Fruits were weighed in each treatment at periodic weighing of 4,9 and $12 \mathrm{~d}$ fruit preservation period (FPP) from beginning, using an electronic balance to 
calculate weight loss during storage. The percent weight loss was calculated as:

$$
\text { Weight } \operatorname{loss}(\%)=\frac{W t-W p}{W t} \times 100
$$

where, $W t=$ weight of fresh fruit after treatment $(\mathrm{g})$ and $W p=$ weight of fruit after preservation $(\mathrm{g})$.

Data were analyzed using SAS statistical package in Duncan's mean separation at $95 \%$ confidence interval.

\section{Results and Discussion}

A. vera gel having various effects on preservation of fruits, such as $\mathrm{pH}$, TSS and weight loss percentage (WLP) are described below.

\section{$3.1 \mathrm{pH}$ Value of Fruit Juice}

$\mathrm{pH}$ values exhibited increasing trend in the control samples with storage period due to the ripening process and loss of organic acid through oxidation in uncoated fruits [10]. Gel acts as an antioxidant [11], so gel coating on fruit acts as a barrier for oxidation. There is a slight deviation in $9 \mathrm{~d}$ FPP and $12 \mathrm{~d}$ FPP with storage time for coated fruits.

Statistical analysis $(P<0.05)$ results in Table 1 showed that in $4 \mathrm{~d}$ FPP, $\mathrm{T}_{4}$ retained the minimum $\mathrm{pH}$ level $(4.697 \pm 0.25)$, followed by $\mathrm{T}_{3}<\mathrm{T}_{2}<\mathrm{T}_{1}$, and non-significant difference was recorded among treatments. In $9 \mathrm{~d}$ FPP and $12 \mathrm{~d}$ FPP, there was also the same pattern of result, the minimum $\mathrm{pH}$ level $(5.0367 \pm 0.76$ and $4.570 \pm 0.30$, respectively) was obtained in $\mathrm{T}_{4}$, followed by $\mathrm{T}_{3}<\mathrm{T}_{2}<\mathrm{T}_{1}$. In $12 \mathrm{~d}$ FPP, there was a significant difference for $\mathrm{pH}$ between the coated fruits and the control fruits.

The possible reason for the variation may be due to the difference in the micro environment created by gel coatings in various percentages used, coupled with less oxidative reactions and lesser decline in degradation of acids, thus maintaining the integrity of cells. These results are in line with Raje et al. [12]. Organic acids are substrates for many enzyme mediated reactions during aerobic respiration in the plant cells, and a reduction in the acidity may be expected as a result of such activity during the preservation period. The decrease in acidity was correlated with the advancement of maturity and ripening in the untreated fruits. The tendency of reduced acidity during storage might be due to that the fruit undergoing the ripening process diminished its malic acid and favored formation of sugars [13]. Another possibility for decrease in acidity is consumption of acid by micro-organisms as a source of carbon. High amount of acidity in treated fruits might be due to facts that carbon dioxide accumulated internally in the fruit tissues caused acidosis after dissolving and forming carbonic acids. These results are also in line with those of Carrillo et al. [14].

\subsection{TSS}

The results of TSS in Table 2 showed that TSS was the highest in control $\left(T_{1}\right)$ as compared with other treatments $\left(T_{2}, T_{3}\right.$ and $\left.T_{4}\right)$. Samples treated with gel showed significantly $(P<0.05)$ lower amount of TSS than control $\left(T_{1}\right)$ in $9 \mathrm{~d}$ FPP and $12 \mathrm{~d}$ FPP. TSS was decreased with increasing gel concentration in the order of $\mathrm{T}_{4}<\mathrm{T}_{3}<\mathrm{T}_{2}<\mathrm{T}_{1}$. In $9 \mathrm{~d}$ FPP, TSS of $\mathrm{T}_{1}, \mathrm{~T}_{2}$ and $\mathrm{T}_{4}$ were significantly $(P<0.05)$ different from each other. In $12 \mathrm{~d}$ FPP, TSS in control $\left(\mathrm{T}_{1}\right)$ was significantly $(P<0.05)$ higher than that from gel treatments $\left(\mathrm{T}_{2}, \mathrm{~T}_{3}\right.$ and $\left.\mathrm{T}_{4}\right)$.

Change in TSS in the present study might be due to the hydrolytic conversion of polysaccharides into soluble sugar, as is the case in mango fruits during the ripening process. In the control $\left(\mathrm{T}_{1}\right)$, rate of conversion of insoluble polysaccharide was faster than the rate of fermentation of mono and disaccharides into organic acids. Therefore, this resulted in an increase in TSS of the fruits. In the gel-coated mango fruits, the rate of conversion of soluble mono and disaccharides into organic acids is faster than the conversion of decreasing trend in TSS. This might be attributed to the microbial activity. The results are in line with the findings of Manzano et al. [15]. 


\subsection{Weight Loss Percentage}

The general trend was an increase in weight loss with decreased concentration of gel. This was true for all preservation periods (4, 9 and $12 \mathrm{~d} \mathrm{FPP})$, which is showed in Table 3. In $4 \mathrm{~d}$ FPP, the highest weight loss percentage $(3.5430 \% \pm 0.48 \%)$ was obtained in control $\left(\mathrm{T}_{1}\right)$ fruits, while the lowest weight loss percentage $(2.6210 \% \pm 0.32 \%)$ was obtained in $\mathrm{T}_{4}$. There was a significant difference between means of control $\left(\mathrm{T}_{1}\right)$ and other treatments $\left(\mathrm{T}_{2}, \mathrm{~T}_{3}\right.$ and $\left.\mathrm{T}_{4}\right)$.

The loss of water from treated fruits was lesser than the control. This was due to the fact that A. vera coating served as semi permeable membrane around fruit surface. Statistical analysis $(P<0.05)$ revealed that in storage period, $T_{1}$ (control) showed the maximum weight loss, followed by $T_{2}>T_{3}>T_{4}$.
However, no significant difference was recorded between $T_{3}$ and $T_{4}$ in $4 \mathrm{~d}$ FPP and $12 \mathrm{~d}$ FPP. In $T_{1}$ (control), an increase in weight loss percentage was recorded with the increased days of preservation, while in fruit of $\mathrm{T}_{4}$, weight loss was decreased at $12 \mathrm{~d}$. In treated fruits, the final decrease in weight loss might be due to the movement of water vapors from the saturated atmosphere into the fruits. These results are in agreement with those of Carrillo-Lopez et al. [16], who observed that coated or uncoated mango in Mexico had an increasing trend of weight loss with the passage of storage time.

Weight loss is an important index of shelf life in the fresh produce. It is mainly attributed to the loss of water during metabolic processes like respiration and transpiration. Moisture loss and gaseous exchange

Table 1 Response of Ampalavi mango fruit pH to various concentration of $A$. vera gel.

\begin{tabular}{llcc}
\hline \multirow{2}{*}{ A. vera gel concentration } & \multicolumn{3}{c}{$\mathrm{pH}$ within fruit preservation period (FPP) } \\
\cline { 2 - 4 } & $4 \mathrm{~d}$ & $9 \mathrm{~d}$ & $12 \mathrm{~d}$ \\
\hline $\mathrm{T}_{1}(0 \%)$ & $4.943 \pm 0.17^{\mathrm{a}}$ & $5.240 \pm 0.36^{\mathrm{a}}$ & $5.430 \pm 0.15^{\mathrm{a}}$ \\
$\mathrm{T}_{2}(33 \%)$ & $4.823 \pm 0.21^{\mathrm{a}}$ & $5.070 \pm 0.71^{\mathrm{a}}$ & $4.860 \pm 0.44^{\mathrm{b}}$ \\
$\mathrm{T}_{3}(66 \%)$ & $4.780 \pm 0.34^{\mathrm{a}}$ & $5.050 \pm 0.78^{\mathrm{a}}$ & $4.630 \pm 0.12^{\mathrm{b}}$ \\
$\mathrm{T}_{4}(100 \%)$ & $4.697 \pm 0.25^{\mathrm{a}}$ & $5.037 \pm 0.76^{\mathrm{a}}$ & $4.570 \pm 0.30^{\mathrm{b}}$ \\
\hline All
\end{tabular}

All the values with the means of three replicates. Means with the same letters in a column are not significantly different according to the Duncan's mean separation at $\alpha=0.05$ and $95 \%$ confidence interval.

Table 2 Change of TSS for Ampalavi mango fruit as influenced by A. vera gel.

\begin{tabular}{llll}
\hline \multirow{2}{*}{ A. vera gel concentration } & \multicolumn{3}{c}{ TSS $\left({ }^{\circ} \mathrm{Bx}\right)$} \\
\cline { 2 - 4 } & $4 \mathrm{~d}$ & $9 \mathrm{~d}$ ithin fruits preservation period (FPP) \\
\hline $\mathrm{T}_{1}(0 \%)$ & $13.667 \pm 1.97^{\mathrm{a}}$ & $17.333 \pm 0.45^{\mathrm{a}}$ & $20.767 \pm 0.65^{\mathrm{a}}$ \\
$\mathrm{T}_{2}(33 \%)$ & $12.733 \pm 0.99^{\mathrm{a}}$ & $15.400 \pm 0.76^{\mathrm{b}}$ & $18.967 \pm 0.60^{\mathrm{b}}$ \\
$\mathrm{T}_{3}(66 \%)$ & $11.333 \pm 2.14^{\mathrm{a}}$ & $14.400 \pm 0.63^{\mathrm{bc}}$ & $18.433 \pm 0.55^{\mathrm{b}}$ \\
$\mathrm{T}_{4}(100 \%)$ & $9.267 \pm 6.30^{\mathrm{a}}$ & $13.967 \pm 0.40^{\mathrm{c}}$ & $18.033 \pm 0.38^{\mathrm{b}}$ \\
\hline
\end{tabular}

All the values with the means of three replicates. Means with the same letters in a column are not significantly different according to the Duncan's mean separation at $\alpha=0.05$ and $95 \%$ confidence interval.

Table 3 Effect of various concentration of $A$. vera gel on weight losses of Ampalavi mango fruits.

\begin{tabular}{llll}
\hline \multirow{2}{*}{ A. vera gel concentration } & \multicolumn{3}{c}{ Weight losses (\%) within fruit preservation period (FPP) } \\
\cline { 2 - 4 } & $4 \mathrm{~d}$ & $9 \mathrm{~d}$ & $12 \mathrm{~d}$ \\
\hline $\mathrm{T}_{1}(0 \%)$ & $3.5430 \pm 0.48^{\mathrm{a}}$ & $7.7690 \pm 2.24^{\mathrm{a}}$ & $8.4570 \pm 4.19^{\mathrm{a}}$ \\
$\mathrm{T}_{2}(33 \%)$ & $3.2232 \pm 0.33^{\mathrm{ab}}$ & $6.1230 \pm 1.37^{\mathrm{ab}}$ & $4.4570 \pm 1.30^{\mathrm{ab}}$ \\
$\mathrm{T}_{3}(66 \%)$ & $2.6718 \pm 0.34^{\mathrm{b}}$ & $5.2259 \pm 0.46^{\mathrm{ab}}$ & $3.2930 \pm 0.42^{\mathrm{b}}$ \\
$\mathrm{T}_{4}(100 \%)$ & $2.6210 \pm 0.32^{\mathrm{b}}$ & $4.5390 \pm 0.87^{\mathrm{b}}$ & $1.1360 \pm 0.63^{\mathrm{b}}$ \\
\hline
\end{tabular}

All the values with the means of three replicates. Means with the same letters in a column are not significantly different according to the Duncan's mean separation at $\alpha=0.05$ and $95 \%$ confidence interval. 
from the fruits are usually controlled by the epidermal layers provided with guard cells and stomata. The $A$. vera gel coating helps to reduce this further, because it forms a film on the top of the skin acting as an additional barrier to moisture loss [17]. These barrier properties also reduce the oxygen uptake by the fruit, which in turn slows down rate of respiration and associated weight loss from the fruit surface. Also it may be due to less availability of ethylene in the storage atmosphere, which in turn decreases the mitochondrial activity and respiration rate, eventually reducing moisture loss from the fruit.

\section{Conclusions}

A. vera gel coating technique prolonged the fruits' shelf life by delaying the ripening. This study proved that the bio-preservative potential of $A$. vera gel in Ampalavi mango fruits. The TSS, $\mathrm{pH}$ and weight loss were differed in coated and uncoated fruits, due to the chemical properties of gel. The mean weight loss, $\mathrm{pH}$ and TSS value of control fruits pulp were higher than that in gel treated fruits. Further studies should be carried out to compare the preservative properties of gel with synthetic preservatives, like benzoic acid.

\section{Acknowledgments}

The authors wish to acknowledge the National Science Foundation's Thematic Research Project on Food Security (NTRP/2012/FS/PG-05/P2) for the financial assistance to this study.

\section{References}

[1] Misir, J., Brishti, F. H., and Hoque, M. M. 2014. "Aloe vera Gel as a Novel Edible Coating for Fresh Fruits: A Review." American J. Food Sci. Tech. 2 (3): 93-7.

[2] Nandal, U., and Bhardwaj, R. L. 2012. "Aloe vera-A Valuable Wonder Plant for Food, Medicine and Cosmetic Use: A Review." Inter. J. Pharm. Sci. Review Res. 13 (1): 59-67.

[3] Kumar, S., and Bhatnagar, T. 2014. "Studies to Enhance the Shelf Life of Fruits Using Aloe vera Based Herbal Coatings: A Review." Inter. J. Agri. Food Sci. Tech. 5 (3): 211-8.

[4] Grundmann, O. 2012. "Aloe vera Gel Research Review:
An Overview of Its Clinical Uses and Proposed Mechanisms of Action." Natural Medicine Journal 4 (9): 93-7.

[5] Science Daily. 2005. "Aloe vera Coating May Prolong Freshness, Safety of Fruits and Vegetables." Accessed September 22, 2005. https://www.sciencedaily.com/releases /2005/09/050922014835.htm.

[6] Ergun, M., and Satici, F. 2012. "Use of Aloe vera Gel as Bio-preservative for 'Granny Smith' and 'Red Chief' Apples." Journal of Animal and Plant Science 22 (2): 363-8.

[7] Serrano, M., Valverde, J. M., Guillén, F., Castillo, S., Martínez-Romero, D., and Valero, D. 2006. "Use of Aloe vera Gel Coating Preserves the Functional Properties of Table Grapes.” J. Agri. Food Chem. 54 (11): 3882-6.

[8] Martinez-Romero, D. L., Alburquerque, N., Valverde, J. M., Guillen, F., Castillo, S., Valero, D., and Serrano, M. 2006. "Postharvest Cherry Quality and Safety Maintenance by Aloe vera Treatment: A New Edible Coating." Postharvest Biology and Technology 39 (1): 93-100.

[9] Valverde, J. M., Valero, D., Martínez-Romero, D., Guillén, F., Castillo, S., and Serrano, M. 2005. "Novel Edible Coating Based on Aloe vera Gel to Maintain Table Grape Quality and Safety.” J. Agri. Food Chem. 53 (20): 7807-13.

[10] Campestre, C., Marsilio, V., Lanza, B., Iezzi, C., and Bianchi, G. 2002. "Phenolic Compounds and Organic Acids Change in Black Oxidized Table Olives." Acta Horticulturae 586: 575-8.

[11] Jumat. 2011. "Aloe vera Gel, Natural Fruit Preservative." Accessed August 26, 2011. http://elecricallearning.blogspot.com/2011/08/aloe-vera-g el-natural-fruit.html.

[12] Raje, L., Sherlekar, S., Ramakrishnan, K., Malshe, V. C., and Subbulakshmi, G. 1997. "Postharvest Preservation of Mangoes by Controlled Chemical Release Agents and Adsorbent." Acta Horticulturae 455: 622-8.

[13] Abbasi, K. S., Anjum, N., Sammi, S., Masud, T., and Ali, S. 2011. "Effect of Coatings and Packaging Material on the Keeping Quality of Mangoes (Mangifera indica L.) Stored at Low Temperature." Pakistan Journal of Nutrition 10 (2): 129-38.

[14] Carrillo, T., Blanco, C., Quiralte, J., Castillo, R., Cuevas, M., and Castro, F. R. 1995. "Prevalence of Latex Allergy among Greenhouse Workers." Journal of Allergy and Clinical Immunology 96 (5): 699-701.

[15] Manzano, J. E., Perez, Y., Rojaz, E., Lavi, U., Dagani, C., Gazit, S., Lahar, E., and Peiss, E. 1997. "Coating Waxes on Haden Mango Fruit (Mangifera indica L.) Cultivate for Export." Acta Horticulturae 455: 738-46.

[16] Carrillo-Lopez, A., Ramirez-Bustamante, F., Valdez-Torres, 
Ampalavi Mango Fruits Using Aloe vera Gel

J., Rojas-Villegas, R., and Yahia, E. 2000. "Ripening and Quality Changes in Mango Fruit as Affected by Coating with an Edible Film.” Journal of Food Quality 23 (5): 479-86.
[17] Togrul, H., and Arslan, N. 2004. "Carboxymethyl Cellulose from Sugar Beet Pulp Cellulose as a Hydrophilic Polymer in Coating of Mandarin." Journal of Food Engineering 62 (3): 271-9. 